\title{
Initial response of the European Society of Paediatric Radiology and Society for Pediatric Radiology to the Swedish Agency for Health Technology Assessment and Assessment of Social Services' document on the triad of shaken baby syndrome
}

\author{
Amaka C. Offiah ${ }^{1} \cdot$ Sabah Servaes $^{2} \cdot$ Catherine S. Adamsbaum $^{3}$. \\ Maria I. Argyropoulou ${ }^{4}$ Katharine E. Halliday ${ }^{5} \cdot \operatorname{Tim~Jaspan~}^{6} \cdot$ Catherine M. Owens $^{7}$. \\ Maria Raissaki $^{8}$ - Karen Rosendahl ${ }^{9}$ - Neil Stoodley ${ }^{10}$ • Rick R. Van Rijn ${ }^{11}$. \\ Michael J. Callahan ${ }^{12}$ - Taylor Chung ${ }^{13}$ • James S. Donaldson ${ }^{14}$ • Diego Jaramillo ${ }^{15}$. \\ Thomas L. Slovis ${ }^{16} \cdot$ Peter J. Strouse $^{17}$
}

Received: 1 February 2017 / Accepted: 10 February 2017 / Published online: 23 February 2017

(C) Springer-Verlag Berlin Heidelberg 2017

To paraphrase the author of a recent editorial, "Abusive neurotrauma exists" [1]. We are therefore concerned by the recent report on the validity of abusive head trauma/shaken baby syndrome commissioned by the Swedish Agency for Health Technology Assessment and Assessment of Social Services (SBU) [2]. This systematic review identified over 3,000 publications, which the experts distilled down to 30 for review, of which only two $[3,4]$ were deemed of up to moderate quality and thus summarized in more detail

Amaka C. Offiah

a.offiah@sheffield.ac.uk

1 Academic Unit of Child Health, University of Sheffield, Room C4, Stephenson Wing Sheffield Children's NHS Foundation Trust Western Bank, Sheffield S10 2TH, UK

2 Department of Radiology, Children's Hospital of Philadelphia, Philadelphia, PA, USA

3 Pediatric Radiology Department, Bicêtre Hospital Paris Sud University, Paris, France

4 Radiology Department, Medical School, University of Ioannina, Ioannina, Greece

5 Paediatric Radiology, Nottingham University Hospitals, Nottingham, UK

6 Neuroradiology, University Hospital, Nottingham, UK

7 Department of Radiology, Great Ormond Street Hospital, London, UK
(Table 4.1, pages 22 and 23 of the report). The report concludes firstly that there is limited scientific evidence that the triad of findings and thus its individual components (subdural hemorrhage, retinal hemorrhage and cerebral edema) indicate the shaken baby syndrome and secondly that there is insufficient scientific evidence to assess the diagnostic accuracy of the triad to identify shaken baby syndrome.

Although we requested it, in letters from Dr Susanna Axelsson (Director General of SBU, DDS, PhD) and

8 Department of Radiology, University Hospital, Heraklion, Crete, Greece

9 Department of Paediatric Radiology, Haukeland University Hospital, Bergen, Norway

10 Paediatric Neuroradiology, Frenchay Hospital, Bristol, UK

11 Department of Radiology, Academic Medical Center, Emma Children's Hospital, Amsterdam, The Netherlands

12 Department of Radiology, Harvard Medical School, Boston Children's Hospital, Boston, MA, USA

13 Department of Diagnostic Imaging, USCF Benioff Children's Hospital Oakland, Oakland, CA, USA

14 Department of Medical Imaging, Ann \& Robert H. Lurie Children's Hospital of Chicago, Northwestern University, Chicago, IL, USA

15 Department of Radiology, Nichlaus Children's Hospital, Miami, FL, USA

16 Diagnostic Imaging, Children's Hospital of Michigan, Detroit, MI, USA

17 Section of Pediatric Radiology, C. S. Mott Children's Hospital, Department of Radiology, University of Michigan Health System, Ann Arbor, MI, USA 
Professor Jan Liliemark (Head of Department, SBU) dated 20 October 2016, we were denied access to review the report prior to publication, on the basis that a careful systematic evaluation of all the available scientific evidence (by a team that included several experts in relevant scientific areas) had been conducted and that therefore our input was not required. In the same letters, Dr Axelsson and Professor Liliemark informed us that the report would be published in Sweden in October and be published in English in "the fall" (autumn) 2016. We have since been informed that the English translation will not be available until spring 2017. As such, we make it clear that we have not yet had access to a formal translation of the report. The published review article [5] summarizes the SBU's findings but does not provide sufficient detail. For example, the quality ratings of the rejected papers are not given and the article is predominantly an overview of the two papers the authors accepted as being of sufficient quality for inclusion in their systematic review. Therefore, until we have had sight of the full report, we can neither endorse the findings nor clarify where we disagree with it.

Given the likely significant international impact of this report in child protection cases, we had hoped that the Swedish Agency for Health Technology Assessment and Assessment of Social Services would publish a translation of the full report before the end of 2016 as promised in their letters to us. Since this has not been the case, we cannot issue a formal position statement. We patiently await the translated report and, in the meantime, end this commentary much as we began: we cannot ignore the concept of abusive neurotrauma in children. It not only exists, but may be increasing in incidence, with associated increases in patient and societal costs [6]. What clinical and imaging features support inflicted head trauma? When there is no skull fracture, does that exclude impact and when there is no impact, if shaking is not the etiology of subdural hemorrhage, then what is? These are the important questions that need to be answered - and although (indeed because) this is an emotive subject, they must be answered robustly and objectively.

Amaka C. Offiah, BSc, MBBS, MRCP, FRCR, PhD. Reader in Paediatric Musculoskeletal Radiology, Department of Oncology and Metabolism, University of Sheffield, Sheffield, UK; Chair, European Society of Paediatric Radiology Child Abuse Taskforce

Sabah Servaes, MD, Department of Radiology, Children's Hospital of Philadelphia, Philadelphia, PA. Chair, Child Abuse Committee, the Society for Pediatric Radiology

Catherine S. Adamsbaum, MD. Chair of the Pediatric Radiology Department, Bicêtre Hospital Paris Sud University, France ESPR; former Co-chair, European
Society of Paediatric Radiology Child Abuse Taskforce; Director, French Child Abuse Diploma (DIU)

Maria I. Argyropoulou, MD, PhD. Professor of Radiology and Head of Radiology Department, Medical School, University of Ioannina, Greece; Secretary General, European Society of Paediatric Radiology; Chair, European Society of Pediatric Radiology Neuroradiology Taskforce

Katharine E. Halliday, MBChB, FRCS, FRCR. Consultant Paediatric Radiologist, Department of Radiology, Queen's Medical Centre, Nottingham University Hospitals, Nottingham, UK; Past Chair, British Society of Paediatric Radiologists

Tim Jaspan, MB, ChB, FRCP, FRCR. Consultant Paediatric Neuroradiologist, Radiology Department, University Hospital, Nottingham, UK

Catherine M. Owens, BSc, MBBS, FRCP, FRCR. Consultant Radiologist, Great Ormond Street Hospital for Children and Reader University College London, London, UK; President, European Society of Paediatric Radiology; Senior Councillor, European Society of Radiology

Maria Raissaki, MD, PhD. Assistant Professor in Pediatric Radiology, Department of Radiology, University Hospital of Heraklion, Crete, Greece; Co-chair, European Society of Paediatric Radiology Child Abuse Taskforce

Karen Rosendahl, MD, PhD. Department of Paediatric Radiology, Haukeland University Hospital, Bergen, Norway; Past President, European Society of Paediatric Radiology

Neil Stoodley, FRCS, FRCR. Consultant Paediatric Neuroradiologist, Frenchay Hospital, North Bristol NHS Trust, UK

Rick R. van Rijn, MD, PhD. Department of Radiology, Emma Children's Hospital, Academic Medical Center Amsterdam, The Netherlands

Michael J. Callahan, MD. Department of Radiology, Boston Children's Hospital, Boston, MA; Secretary, Society for Pediatric Radiology

Taylor Chung, MD. Department of Diagnostic Imaging, University of California-San Francisco Benioff Children's Hospital Oakland, Oakland, CA. First Vice President, Society for Pediatric Radiology

James S. Donaldson, MD. Chair, Department of Medical Imaging, Ann and Robert H. Lurie Children's Hospital, 
Chicago, IL; Chairman of the Board of Directors and Past President, the Society for Pediatric Radiology

Diego Jaramillo, MD. Department of Radiology, Nichlaus Children's Hospital, Miami, FL; President, Society for Pediatric Radiology

Thomas L. Slovis, MD. Department of Radiology, Children's Hospital of Michigan, Detroit, MI; Past President, Society for Pediatric Radiology

Peter J. Strouse, MD. Director, Section of Pediatric Radiology, C.S. Mott Children's Hospital, University of Michigan Health System, Ann Arbor, MI. President-elect, Society for Pediatric Radiology

\section{Compliance with ethical standards}

Conflicts of interest None

\section{References}

1. Strouse PJ (2016) Child abuse: we have problems. Pediatr Radiol 46: 587-590

2. Swedish Agency for Health Technology Assessment and Assessment of Social Services (2016) Skakvåld — Triadens roll vid medicinsk utredning av misstänkt skakvåld. En systematisk översikt statens. http://www.sbu.se/sv/publikationer/SBUutvarderar/skakvald-triadens-roll-vid-medicinsk-utredning-avmisstankt-skakvald/. Accessed 23 Jan 2017

3. Vinchon M, de Foort-Dhellemmes S, Desurmont M et al (2010) Confessed abuse versus witnessed accidents in infants: comparison of clinical, radiological and ophthalmological data in corroborated cases. Childs Nerv Syst 26:637-645

4. Adamsbaum C, Grabar S, Mejean N et al (2010) Abusive head trauma: judicial admissions highlight violent and repetitive shaking. Arch Pediatr 126:546-555

5. Lynoe N, Elinder G, Hallberg B et al (2017) Insufficient evidence for "shaken baby syndrome" - a systematic review. Acta Paediatr. doi: 10.1111/apa. 13760

6. Boop S, Axente M, Weatherford B et al (2016) Abusive head trauma: an epidemiological and cost analysis. J Neurosurg Pediatr 18:542549 